\title{
Biliary Ascariasis: An Unusual Cause of Biliary Colic
}

\author{
Ousmane Thiam ${ }^{1 *}$, Mohamadou Lamine Gueye ${ }^{1}$, Alpha Oumar Toure ${ }^{1}$, Mamadou Seck ${ }^{1}$, \\ Lera Geraud Akpo², Hamidou Deme ${ }^{2}$, Mamadou Cisse', Ousmane Ka1, Madieng Dieng1, \\ Abdarahmane Dia', Cheikh Tidiane Toure ${ }^{1}$ \\ ${ }^{1}$ General Surgery Department, Aristide Le Dantec Hospital of Dakar, Dakar, Senegal \\ ${ }^{2}$ Radiology Department, Aristide Le Dantec Hospital of Dakar, Dakar, Senegal \\ Email: o thiam@hotmail.fr
}

Received 5 October 2015; accepted 22 October 2015; published 28 October 2015

Copyright (C) 2015 by authors and OALib.

This work is licensed under the Creative Commons Attribution International License (CC BY).

http://creativecommons.org/licenses/by/4.0/

(c) (i) Open Access

\begin{abstract}
Introduction: Ascariasis by Ascaris lumbricoides is a cosmopolitan disease. Biliary ascariasis is unusual in our country. We report a case of biliary ascariasis revealed by biliary colic. Observation: A 22-year-old woman with no particular history was received for biliary colic associated to vomiting without fever or bowel disorders. On examination, there were pain and defense at the right upper quadrant and a Murphy sign. Moreover, the clinical examination was normal. Blood cells count, renal function, liver function, coagulation and blood ionogram were normal. The abdominopelvic ultrasonography showed a probable parasitosis of the bile duct with gallbladder sludge and dilatation of the common bile duct. The abdominopelvic CT scan revealed intrahepatic and common bile duct (CBD) dilatation and organic image in the common bile duct. Right subcostal laparotomy was allowed to extract an ascaris blocking the common bile duct. A cholecystectomy and drainage of the bile duct with a Kehr drain were performed. The postoperative course was marked by wound surgical suppurative resolved by treatment. She was discharged on the $9^{\text {th }}$ post-operative day. T-tube was removed on the $21^{\text {st }}$ post-operative day after normal cholangiography. Conclusion: Biliary ascariasis is rare in our regions. The diagnosis must be kept in mind in case of biliary colic and ultrasound confirm the diagnosis. Surgical treatment gives good results in our regions.
\end{abstract}

\section{Keywords}

Ascariasis, Biliary Ascarisis, Cholecystitis, Pancreatitis, Cholangitis

Subject Areas: Surgery \& Surgical Specialties

\footnotetext{
${ }^{*}$ Corresponding author.
}

How to cite this paper: Thiam, O., Gueye, M.L., Toure, A.O., Seck, M., Akpo, L.G., Deme, H., Cisse, M., Ka, O., Dieng, M., Dia, A. and Toure, C.T. (2015) Biliary Ascariasis: An Unusual Cause of Biliary Colic. Open Access Library Journal, 2: e2003. 


\section{Introduction}

Ascariasis by Ascaris lumbricoides is a cosmopolitan disease, especially in hot and humid low-income countries [1]. Biliary ascariasis is rare in our regions. However, it is common in India where it is endemic in the Kashmir Valley [2] [3]. Biliary ascariasis symptomatology is variable, ranging from a biliary colicto cholangitis. Ultrasound has a very good sensitivity for the diagnosis [4]. We report a case of biliary ascariasis revealed by biliary colic.

\section{Case Report}

A 22-year-old woman without particular history presented at our emergency unit for a right upper quadrant pain, blocking breathing associated with vomiting without fever or bowel disorders. The temperature was $37.7^{\circ} \mathrm{C}$, pulse rate 98 beats $/ \mathrm{mn}$, respiratory rate 24 cycles/mn and blood pressure 110/70 $\mathrm{mmHg}$. There were pain and defense at the right upper quadrant with a Murphy sign. Moreover, the clinical examination was normal. The white blood cells rate was $7800 / \mathrm{mm}^{3}$, hemoglobin's rate $14.7 \mathrm{~g} / \mathrm{dl}$, platelet's rate $287000 / \mathrm{mm}^{3}$ and hematocrit $46 \%$. The renal function, liver function, coagulation, and blood ionogram were normal. The abdominopelvic ultrasonography showed a probable parasitosis of the bile duct extended to the upper biliary confluence with gallbladder sludge and dilatation of the common bile duct to $13 \mathrm{~mm}$ (Figure 1). The abdominopelvic CT scan showed an intra and extrahepatic duct dilatations and tissular image in the common bile duct (Figure 2). Right subcostal laparotomy exploration showed gallbladder and main bile duct dilatation. Cholecystectomy and longitudinal choledocotomy allowed to extract a living female worm measuring $20 \mathrm{~cm}$ long obstructing the common bile duct. We extracted the worm through the incision and performed a common bile duct drainage with a Kehr drain (Figure 3 and Figure 4). She was treated by albendazol $400 \mathrm{mg}$ per day during 3 days. The postoperative course was marked by surgical wound infection well treated with antibiotics and daily dressings. Kehr drain was clamped to $9^{\text {th }}$ postoperative day. She was discharged on $12^{\text {th }}$ postoperative day. Cholangiography by the T-tube was performed at $21^{\text {st }}$ postoperative day without abnormalities allowing the removal of the drain (Figure 5).

\section{Discussion}

Biliary ascariasis is rare in our regions. It can be found at any age but especially in children and young adults as in our patient [5]-[7]. The migration of Ascaris lumbricoides in the biliary ducts is the most common surgical complication of ascariasis [6]. According to Sandouk F. et al., in patients with biliary ascariasis, cholecystectomy and endoscopic sphincterotomy are risk factors accounting respectively in $80 \%$ and $77 \%$ [1]. Endoscopic

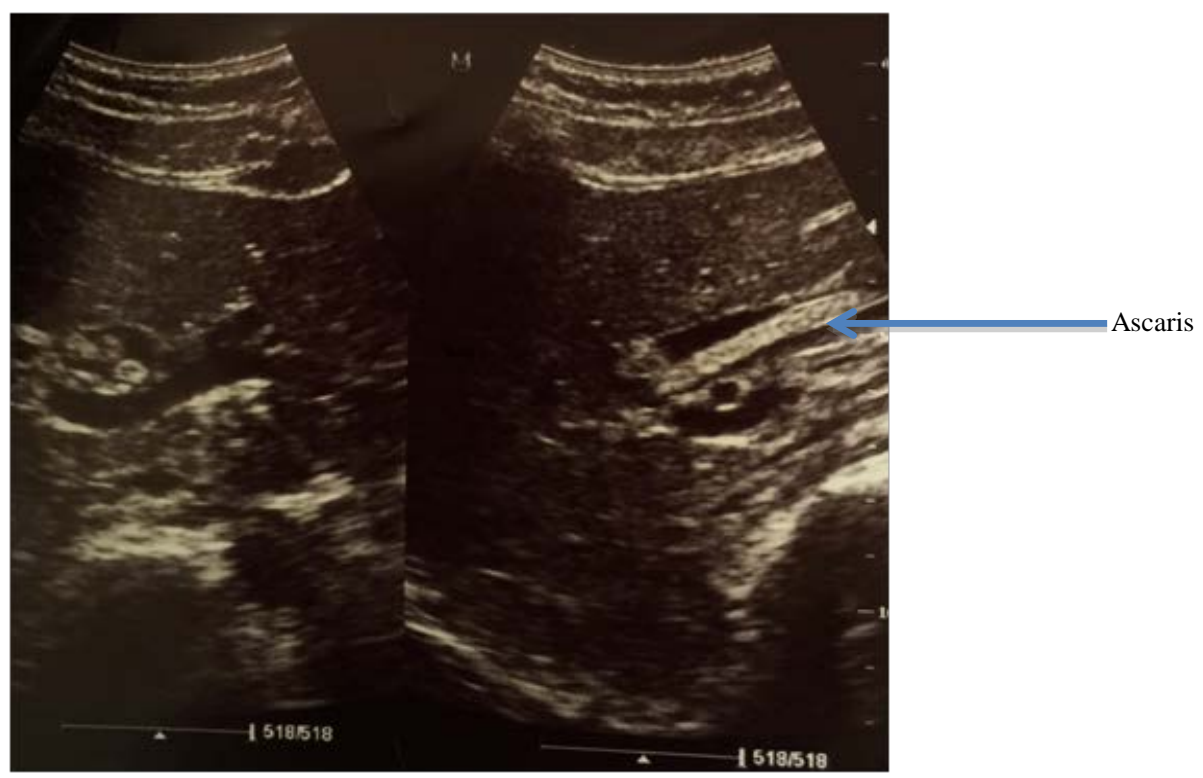

Figure 1. Abdominopelvic ultrasound suspecting parasitosis of the CBD with gallbladder sludge and dilatation of the CBD. 
O. Thiam et al.

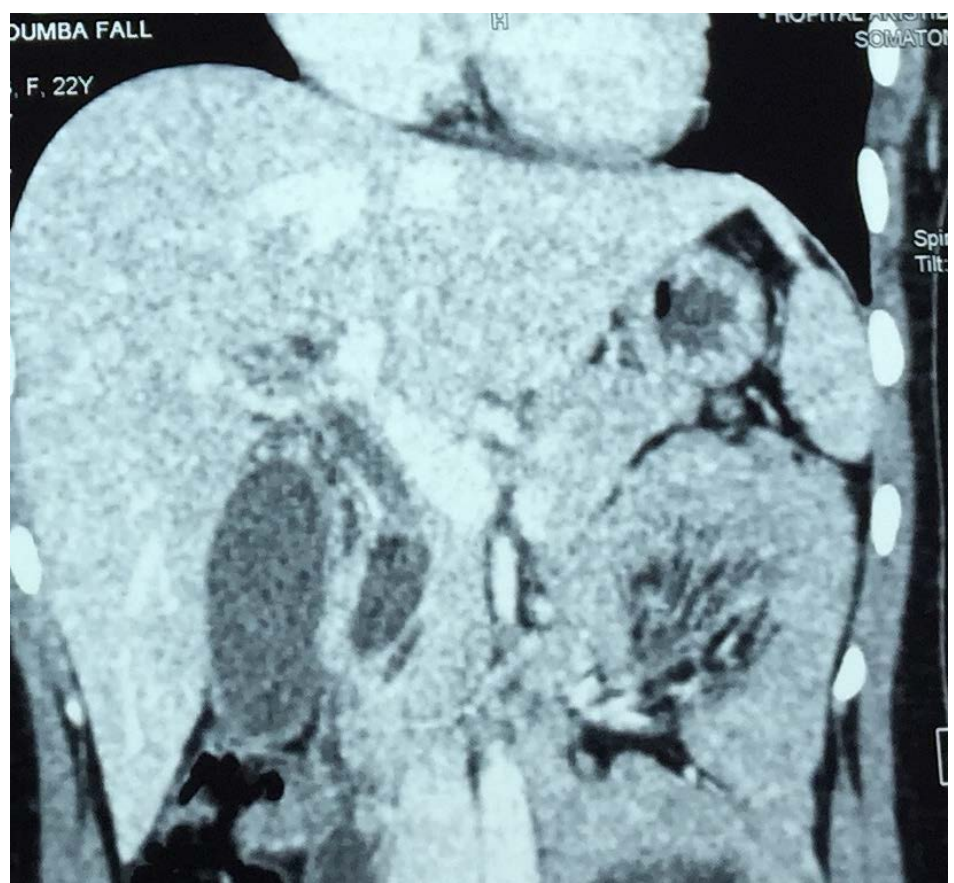

Figure 2. Abdominopelvic CT scan showing dilatation of the intra and extrahepatic biliary tract and tissular image in the CBD.

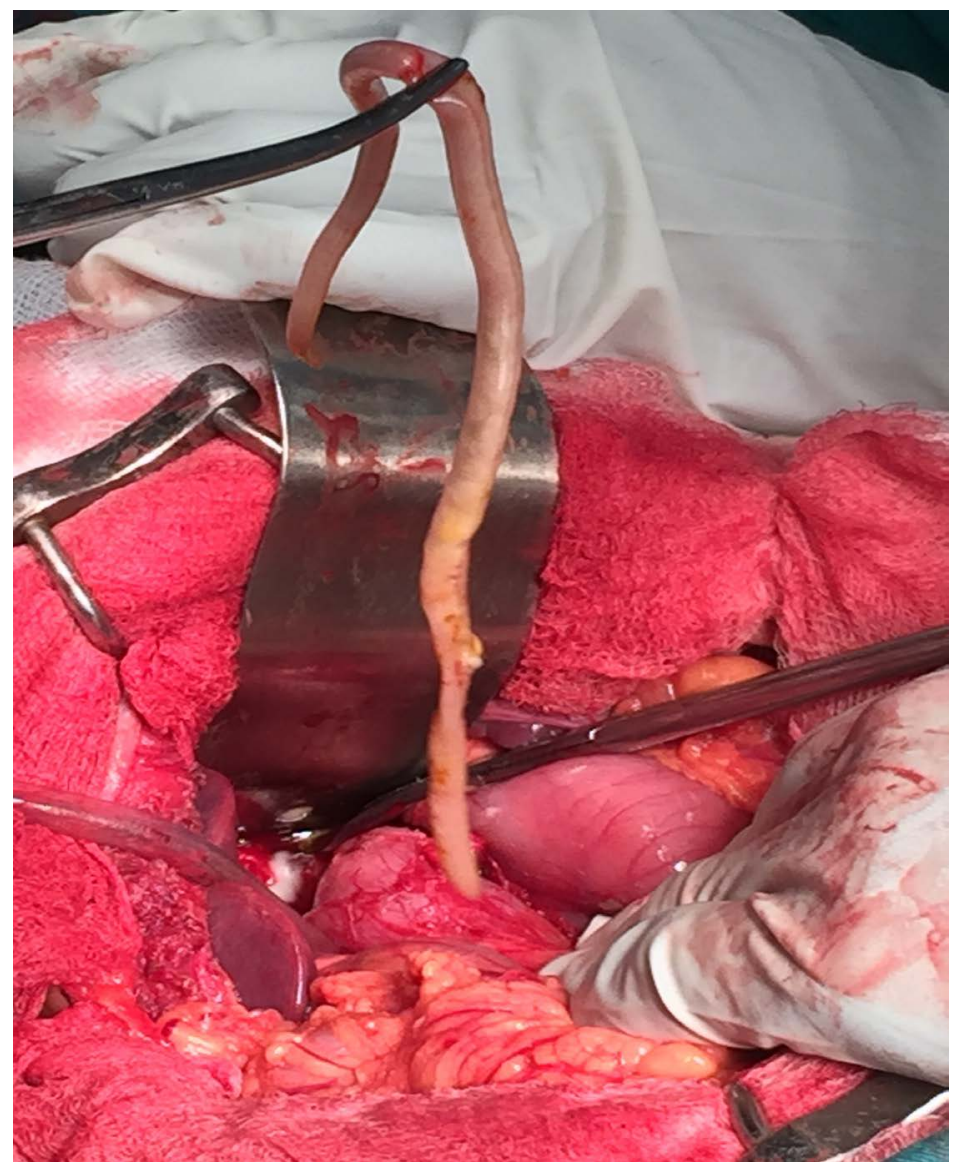

Figure 3. Per-operative view showing extraction of the ascaris. 


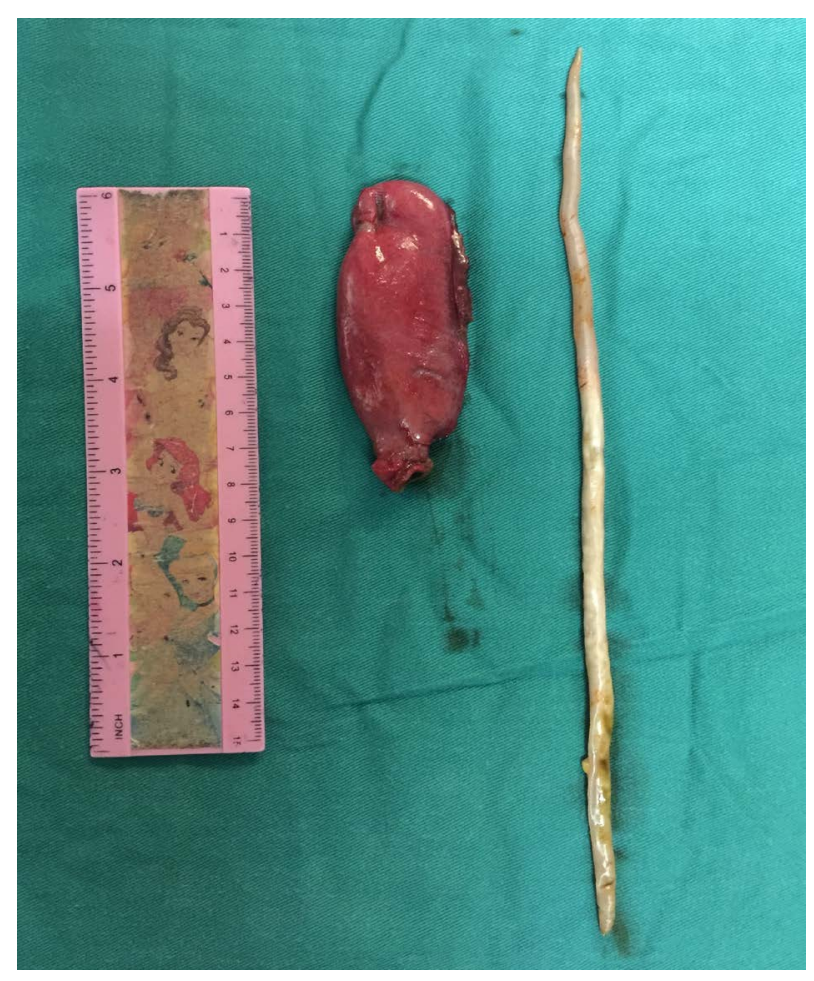

Figure 4. Living female ascaris mesuring $20 \mathrm{~cm}$ and the gallbladder.

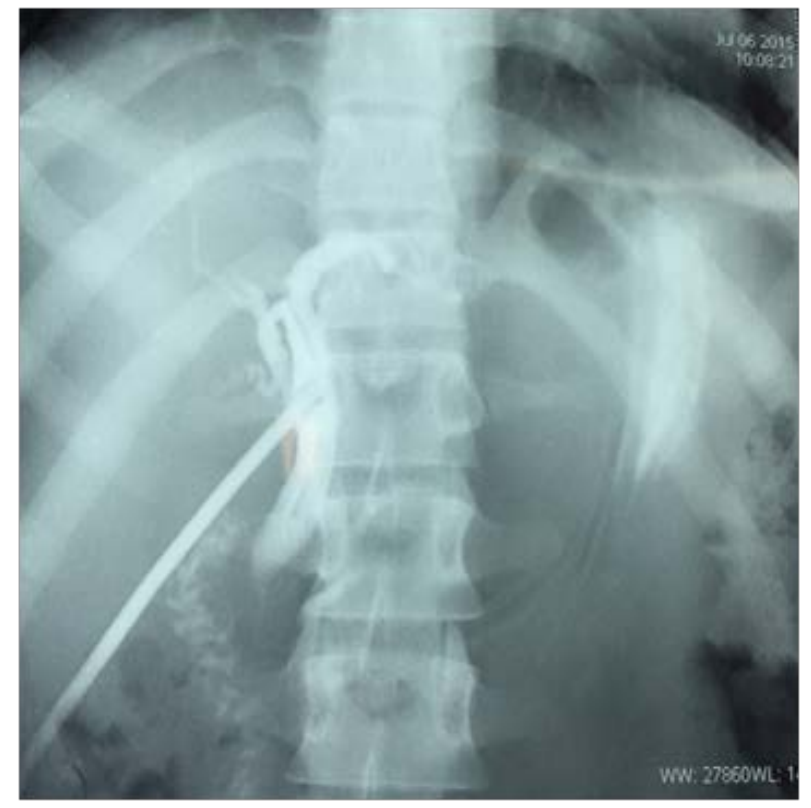

Figure 5. Cholangiography by the T-tube.

sphincterotomy induced sphincter of Oddi relaxation promoting migration of worm into the biliary tree. The symptoms are variable. Its diagnosis may be accidental during ultrasonography or cholecystectomy [6]. It can be revealed by recurrent biliary colic, cholecystitis, cholangitis, liver abscesses and pancreatitis [1] [6]. The death of roundworms in the bile duct may lead to inflammation of the mucosa then a stricture [6]. It raises the differential diagnosis with gallstone disease especially in our regions where it is rare. The particularity in our patient 
was an inaugural picture at the stage of biliary obstruction. Eosinophilia oriented towards parasitosis without specifying the site. The certitude diagnosis is made in case of detection of the parasite in the stool or in the duodenum during endoscopy [6]. In endemic countries like India, the diagnosis is made by clinical examination, ultrasound and endoscopy [6]. In our patient, the diagnosis was early made by clinic examination and ultrasound. Ultrasound made the diagnosis by showing a linear or curvilinear echogenic structure, single or multiple tube with a central void like spaghetti, without posterior shadowing as found in our patient [5] [8]. There are also dilatation of intra and extrahepaticbiliary ducts. Roundworm can also appear as a pseudotumor [5] [8]. CT scan is used to exclude liver and pancreatic pathology in cases of indirect signs of dilatation of the bile duct. However, on CT scan and ultrasound, the main differential diagnosis are tumors and gallstones [6]. Medical treatment consisted on diet, intravenous administration of antibiotics and antispasmodics to remove the round worm of the biliary tract [4]. In case of medical treatment, anthelmintics should not be administered because they could lead to roundworms death in the bile duct [6]. Persistent clinical signs after 72 hours of medical treatment indicated performing endoscopy or surgery [6]. The endoscopic retrograde cholangiopancreagraphy (ERCP) is an excellent therapeutic mean for extracting roundworm through the duodenal papilla with a high rate of success and low complication rates [1] [4] [6]. Surgery is indicated in case of failure of endoscopic treatment, of liver abscesses, gallbladder roundworms, intrahepatic roundworm and severe acute pancreatitis. Procedure will consist of cholecystectomy, choledocotomy with worm extraction and drainage of the bile duct with a T-tube as performed in our patient. Some authors provide biliary bypass such as choledocho-duodenostomy, choledocho-jejunostomy, hepatico-jejunostomy. In rare cases of intra-hepatic ascarisis, hepatectomy may be indicated [2] [3]. Surgical treatment in our patient was justified by the unavailability of ERCP.

\section{Conclusion}

Biliary ascariasis is rare in our regions. The diagnosis should be kept in mind in case of biliary colic. Ultrasound is a good tool diagnosis in low-income countries. Surgical treatment is a good indication in our regions.

\section{Conflict of Interest}

None declared.

\section{References}

[1] Sandouk, F., Haffar, S., Zada, M.M., Graham, D.Y. and Anand, B.S. (1997) Pancreatic-Biliary Ascariasis: Experience of 300 Cases. American Journal of Gastroenterology, 92, 2264-2267.

[2] Pilankar, K.S., Amarapurkar, A.D., Joshi, R.M., Shetty, T.S., Khithani, A.S. and Chemburkar, V.V. (2003) Hepatolithiasis with Bilary Ascaris-A Case Report. BMC Gastroenterology, 3, 35. http://dx.doi.org/10.1186/1471-230X-3-35

[3] Ibrarullah, Md., Mishra, T., Dash, A.P. and Upadhaya, U.N. (2011) Biliary Ascariasis—Role of Endoscopic Intervention. Tropical Gastroenterology, 32, 210-213.

[4] Al Absi, M., Qais, A.M., Al Katta, M., Gafour, M. and Al-Wadan, A.H. (2007) Biliary Ascariasis: The Value of Ultrasound in the Diagnosis and Management. Annals of Saudi Medicine, 27, 161-165. http://dx.doi.org/10.4103/0256-4947.51511

[5] Misra, S.P. and Dwivedi, M. (2000) Clinical Features and Management of Biliary Ascariasis in a Non-Endemic Area. Postgraduate Medical Journal, 76, 29-32. http://dx.doi.org/10.1136/pmj.76.891.29

[6] Jethwani, U., Singh, G.J., Sarangi, P. and Kandwal, V. (2012) Laproscopic Management of Wandering Biliary Ascariasis. Case Reports in Surgery, 2012, 561-563. http://dx.doi.org/10.1155/2012/561563

[7] Manning, R.G. and Tani, M.K. (2009) Management of Biliary Ascaris Lumbricoides in Kabul, Afghanistan: Crossroads of Advancing Technology. BMJ Case Reports, 2009, bcr0720092138. http://dx.doi.org/10.1136/bcr.07.2009.2138

[8] Wu, S. (2009) Sonographic Findings of Ascaris Lumbricoides in the Gastrointestinal and Biliary Tracts. Ultrasound Quarterly, 25, 207-209. http://dx.doi.org/10.1097/RUQ.0b013e3181c47a2d 